\title{
Representing people, constituting worlds: multiple 'Neolithics' in the Southern Balkans
}

\author{
Stratos Nanoglou \\ Department of History, Archaeology and Social Anthropology, University of Thessaly, Volos, GR \\ nanoglou@hist.auth.gr
}

\begin{abstract}
This paper considers the diverse iconographic landscapes of the southern Balkans, especially those populated by human figurines. The main premise is that material culture is a resource upon which agents draw to situate themselves in the world. In this way, regional traits are deemed particularly important for the constitution of specific subjectivities, in contrast to a generic 'Neolithic individual', and at the same time, for the constitution of specific local worlds as opposed to an all-encompassing world that is merely experienced differently. I attempt to provide an example of such regional traits that would have constituted different contexts for agency during the Neolithic and focus on the differences between two regions within the southern Balkans, regions that do not remain the same in the course of time.
\end{abstract}

IZVLEČEK - Članek preučuje različne neolitske ikonografske krajine južnega Balkana, zlasti tiste, ki jih poseljujejo človeške figurine. Glavna predpostavka je, da je materialna kultura vir, s katerim se delovanja umeščajo $v$ svet. Na ta način so regionalne poteze posebej oblikovane v posebne subjektivitete, ki delujejo kot nasprotja generični 'neolitski individualnosti'. Oblikujejo tudi posebne lokalne svetove kot nasprotek drugače doživetemu vse-obsegajočemu svetu. Poskušam predstaviti primer takšnih regionalnih potez, ki v neolitiku oblikujejo različne kontekste delovanja in se osredotočiti na razlike med dvema regijama na južnem Balkanu, ki sta se skozi čas spreminjali.

KEY WORDS - representation; figurines; regionalism; materialization

\section{Introduction}

The usual approach to prehistoric imagery is essentialist in character. Figurines and other representations of humans, animals and other entities are considered products of an inner 'ideological' or 'nonpractical' behaviour, which is separated from the rest of social life and is presumed to illuminate the mental activity or even capacity of the people that used the artefacts. Representations of any kind are still approached as an inherent facet of humanity, albeit of a certain stage of humanity's evolution. It is not fortuitous that the earliest representations made by humans are still equated with art and, consequently, are taken as an index of civilization, of people ascending to the next level of their long walk toward the present (see for instance Renfrew's (2003.13) recent argument: 'We [sapiens ancestors of 40000 years ago and modern humans in Europe today] are pretty much the same. This is partly illustrated by the remarkable cave art that appeared in France and Spain').

The equation of certain artefacts with a certain stage and, therefore, with a certain 'economic' behaviour characterizes all sorts of periodizations and classifications. Although making representations is not a trait of each and every society, attempts to gather different societies under a common denominator are still considered valid (e.g. Renfrew 2007.xv). Yet, in these cases, even though representations were the very criterion for assembling the different societies under the same roof, the distinctive trait refers again to other fields ('sedentism', 'hierarchy', Ren- 
frew 2007.xvi). As far as the Neolithic is concerned, here too the common agricultural regime presupposes that material culture, and that includes representations as well, performs the same functions across the regions where they are found. Representations are considered a by-product of the evolution of humanity, of its capacity, that is, to reify abstract ideas which are bound to be part of its parcel at some point in time. Irrespective of when each and every trait appears in the 'archaeological record', the inescapable conclusion is that a common 'economic' background would mean a common range of 'beliefs' incarnated in the representations of the period: Neolithic representations are first and foremost Neolithic, which means that the Neolithic is already constituted before representations enter the scene. When they do, they appear merely as representatives of the common regime, with no power over it. It is as if they were made solely to inform others of people's intentions, to serve as mirrors of one's inner self.

Contrary to this view, I make a plea to change the order and consider the 'Neolithic' as the by-product of the use of representations. It is time to abandon the implicit idea that artefacts are reflections of past intentionalities and, instead, interpret material culture as a resource upon which agents draw in order to situate themselves in the world (Barrett 2005). In each and every case where artefacts that represent people, animals or other entities are used, they are constitutive of the framework which guides people's actions, and are not merely a manifestation of it. In this way, regional traits are deemed particularly important for the constitution of specific subjectivities in contrast to a generic 'Neolithic individual'. If representations are different, then their world is different, not because they bear witness to different beliefs, but because they are part of the materials that built that world. In this paper, I try to provide an example of such regional traits that would have constituted different contexts for agency during the Neolithic, and take up the case of the southern Balkans, from northern Greece to Serbia.

\section{How to do things with figurines}

How is it that representations constitute a way of life for their users? There is much debate over the relation of people with material culture, a debate usually formed around the idea of the mutual con-

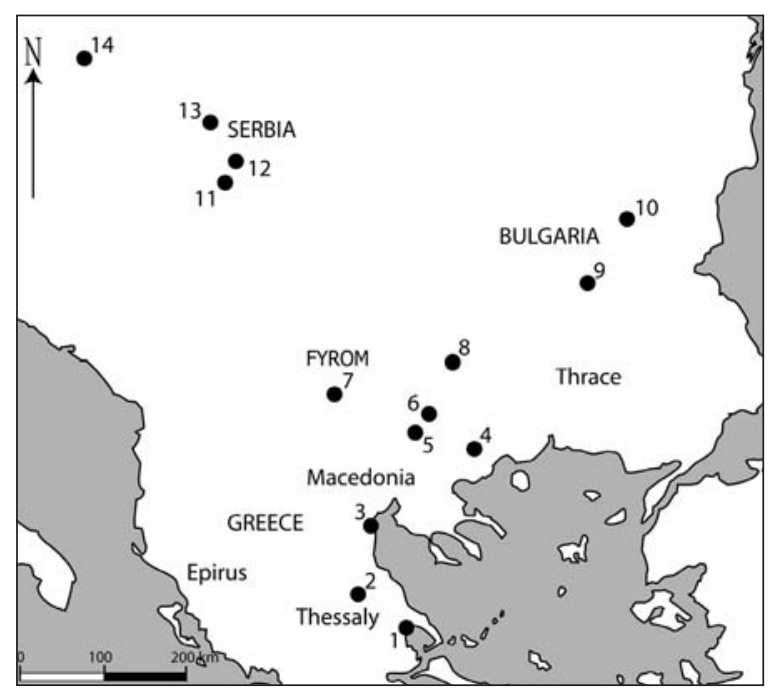

Fig. 1. Map with areas and sites discussed in the text: 1. Dimini; 2. Platia Magoula Zarkou; 3. Makriyalos; 4. Sitagroi; 5. Promachon-Topolniča; 6. Kovačevo; 7. Anza; 8. Rakitovo; 9. Karanovo; 10. Ovčarovo; 11. Divostin; 12. Selevac; 13. Vinča; 14. Donja Branjevina.

stitution of people and things. Even though this debate began with some very powerful theoretical propositions, admittedly with an extremely careful articulation, in order not to reify the two parts of the equation (Miller 1987; see also Miller 2005; Meskell 2004), usually in archaeology, and indeed in the subfield of representational practices (usually called 'art'), the theoretical exposition takes the form of a simple to-and-fro relation between the two parts, whereby people make things and things have an effect on people. In this formulation, people are affected by artefacts only after their production, their ascension to full-fledged things. Meanwhile, the process is rather absent from the discussion, as are artefacts that have not successfully reached the end of the process. Infelicitous actions do not count, since they are not 'imbued with the intention of the producer' (Mina 2008.116; citing Knappett 2006.240, who, however, focuses on the process of manufacture and speaks of imbuing with mindfulness, rather than intention). And yet, arguably all production is infelicitous, for nothing can be said to correspond exactly to some predisposed intentions of the producer (Butler 1993; Barrett 2005; Felman 2003) ${ }^{\mathbf{1}}$. Products are bound to fail to materialize an intention, and this makes change possible. In a nutshell, separating the formation of intentions from the actual manufacture of things hardly suggests the mutual constitution of people and things. Contrary

1 For the concept of felicitous and infelicitous (speech) acts, see Austin 1962, from which the section title is evidently borrowed, and Derrida 1982, Felman 2003, Butler 1997. 
to that, the constitution of intentions should be situated within the manufacturing process (Joyce 2000; Nanoglou 2008a.2-3). As Miller points out, 'our humanity is not prior to what it creates' (Miller 2005. 10; see also Nanoglou 2008b.314), and thus our constitution as subjects is coextensive with the constitution of other entities such as animals, plants or things, etc. This is an unceasing process, but it 'stabilizes over time to produce the effect of boundary, fixity, and surface we call matter' (Butler 1993.9, emphasis removed). In this, it draws upon earlier processes, earlier stabilizations, earlier boundaries and surfaces, which it rearticulates into new, yet conditioned ones.

Representations are such entities that stabilize over time in a certain form. Their materialization is an endless process (Meskell 2007), but one which, as a result of the discourses structuring each context, produces different 'matters'. The very categorization of artefacts today is the result of specific discourses that dominate the field of archaeology, and we can imagine that figurines might have not been a coherent or intelligible category of artefacts in the past (Meskell 1995; Ucko 1996). Again, we should not conceptualize discourses as pre-existing structures that produce simple manifestations of themselves. Discourses are entirely coextensive with their being practiced and performed, which is why they never attain closure (Nanoglou 2008b.314). In this vein, representations are performative articulations, i.e. they do not stand merely for an abstract set of rules, but actually materialize discourses, which on the other hand cannot exist outside this materialization.

In the process of constituting themselves, then, people draw upon such articulations, performing and materializing discourses that also inform and govern the materialization of entities such as figurines, anthropomorphic and zoomorphic vessels, or any other relevant artefact. By studying the patterns of the production and use of all these artefacts we can reconstruct (at least partially) some of the discourses that governed the production of human subjects, focusing on their performative power - their capacity to produce what they describe, be it a human body or a certain animal, in flesh or in clay.

This process always takes place in specific conditions, it is always local (Whittle 2003; citing Latour 1993) and produces particular 'fields of time-space' (Barrett 1994. 72) or 'spacetimes' (Munn 1986.9-11, see Nanoglou 2006.157), because the circumstances in which people, animals, actions and material culture converge are unique, and so are the rearticulations of these moments. These moments are reference points for the configuration of people's lives; the practices that were performed there acted as guidelines for new ones. This means, of course, that in each case a different set of practices was called upon as reference matter; a new world was constituted, a world anchored in and conditioned by the references, but still a world that had broken away from these reference points. The more faithful the reiteration of the referent, the more powerful became both the referent and the referring act. On the one hand, commemorating moments in various fields, extending the spacetime (Munn 1980), amounted to reinforcing their position as reference points, raising them to the level of dominating discourse. On the other hand, this made the reiteration of the moments intelligible and acceptable, even desirable.

Within this framework, representations both commemorate and are commemorated. They reiterate previous practices, whether the manufacture of another artefact, someone's action or disposition etc., and they stand as reference points for practices to come, be they the manufacture of another artefact, someone's action or disposition etc. They do this from specific positions, having a specific materiality, a specific material presence. Figurines are small and handy; vessels in the form of a human or an animal serve as containers too; big statues are relatively immovable and easier to see and so forth. They take part in various social fields in different ways and are brought to bear upon people's lives according to specific biographies, both their own and their users'. From this point of view, the lives of their users are bound to be similar - having to draw upon interconnected spacetimes - and different, having always to choose and fail to reiterate identically specific spacetimes.

In this paper, I am going to pursue this line of thought in considering the representational practices of the middle and southern Balkans during the Neolithic, i.e. the area of Greece, particularly northern Greece (primarily the areas of Thessaly and Macedonia, as there is not much information on Epirus or Thrace), the former Yugoslavia, and Bulgaria (but not northeastern Bulgaria in the later Neolithic, which follows a different trajectory). I will focus on the ways humans are represented in these areas during the Neolithic and the consequences that any similarities or any differences might have had for the lives of their respective inhabitants. The exploration will focus on the differences between two regions, 
a northern and a southern one, which will include different modern areas during time. Although the paper is about regional differences, in the course of this text I will leave out of the discussion any variability within each region and treat them generically. This is due to space and research limitations, and I fully acknowledge that this variability is essential to any fuller understanding of the life of the inhabitants of the regions (see also Nanoglou 2006). I hope that the approach advocated here will remain valid in any prospective examination of smaller or greater regions. For similar reasons, I will explore the case within a two-phase timeframe, distinguishing between an earlier and a later Neolithic. The former will refer to the Early Neolithic of the central Balkans (or 'Starčevo culture') and the Early and Middle Neolithic of northern Greece (or 'Protosesklo' and 'Sesklo culture', respectively) and the latter to the Late Neolithic of the central Balkans ('Vinča culture') and northern Greece ('Dimini culture') 2 . In calendrical years, the earlier Neolithic more or less spans the seventh and the first half of the sixth millennium BC, and the later Neolithic, the second half of the sixth and the fifth millennium BC (Andreou et al. 1996; Reingruber and Thissen 2005).

\section{Diversified beginnings: the earlier Neolithic}

Although hardly constituting a beginning per se, like any other period for that matter, the earlier Neolithic will serve here as the beginning of my exploration. On an analytical level, the changes observed during this time have been given much credit, to the point of even talking about a revolution. I do not mean to suggest that there were not profound changes taking place during this time in the area under consideration. On the contrary, there were significant departures from earlier traditions: new types of settlement, new types of artefacts, new types of resources (see Bailey 2000). But the important issue is not to see these novelties as exhibiting new technologies, that is, as the dissemination of some kind of new knowledge, but as the emergence of new relations between the inhabitants (Whittle 2001), relations that included animals, plants and things. Among those things, there were many objects that represented humans: figurines, vessels in the form of humans or with human-shaped add-ons, pendants and other items. Figurines, i.e. objects that represent humans, but which are not pendants, receptacles, or attached to receptacles, constitute by far the largest category, and I will concentrate on them in the remainder of the paper. 3 They seem to be omnipresent, even if their distribution is not without variation. There are sites that have produced thousands, and sites that have produced a mere handful (Nanoglou 2006 for Greece, but the same applies to the North).

Admittedly we are somewhat at a disadvantage regarding any knowledge of their context of use (see Nanoglou 2008a.3-4 for a discussion). There are not many publications with detailed information on the context of discovery. Most of the objects found in an undisturbed layer come from refuse deposits, which at least tell us something about the end of their life. In northern Greece, there are a few occurrences of figurines deposited in groups, but there is no way of knowing whether this was a widespread practice (but see below). Thus iconography remains the most promising avenue of investigation and, interestingly, the area where differences between regions emerge most clearly.

During the earlier Neolithic, almost all figurines were made from clay (Nanoglou 2008b). However, there are two major differences between the assemblages excavated in the central Balkans and those excavated in Greece: the first has to do with the ratio of humans versus animals, and the other with the way humans were represented in the two regions (for a fuller discussion see Nanoglou 2008a). Although my main concern rests with human figures, the two differences are interconnected, and both need to be taken into consideration. In both areas, human figurines predominate, but while in the assemblages from the central Balkans ('Starčevo' assemblages) we find a ratio of humans to animals fluctuating from $2: 1$ to $4: 1$, in northern Greece the ratio rises to fluctuate from 10:1 to 15:1, and in certain cases animal figurines are non-existent (Nanoglou 2008a.5). Thus in the central Balkans, there is a significant concern with animals, whereas in northern Greece the iconographic landscape is overtly anthropocentric, at least when it comes to figurines.

2 The equation of the Greek Late Neolithic with the 'Dimini culture' is not wholly accurate any more. In fact the so-called 'Dimini phases' correspond to the second half of the Late Neolithic. The first half is called 'pre-Dimini phases'. It should be borne in mind that many of the traits of the 'Dimini phases' continue in use in the ill-defined Final Neolithic period.

3 There are reasons, besides the presence of a hole, to differentiate between figurines and pendants, at least in Neolithic Thessaly (Nanoglou 2005.144 and especially Nanoglou 2008b.317). The differentiation between anthropomorphic figurines and vessels is for the moment mostly an analytical one. 


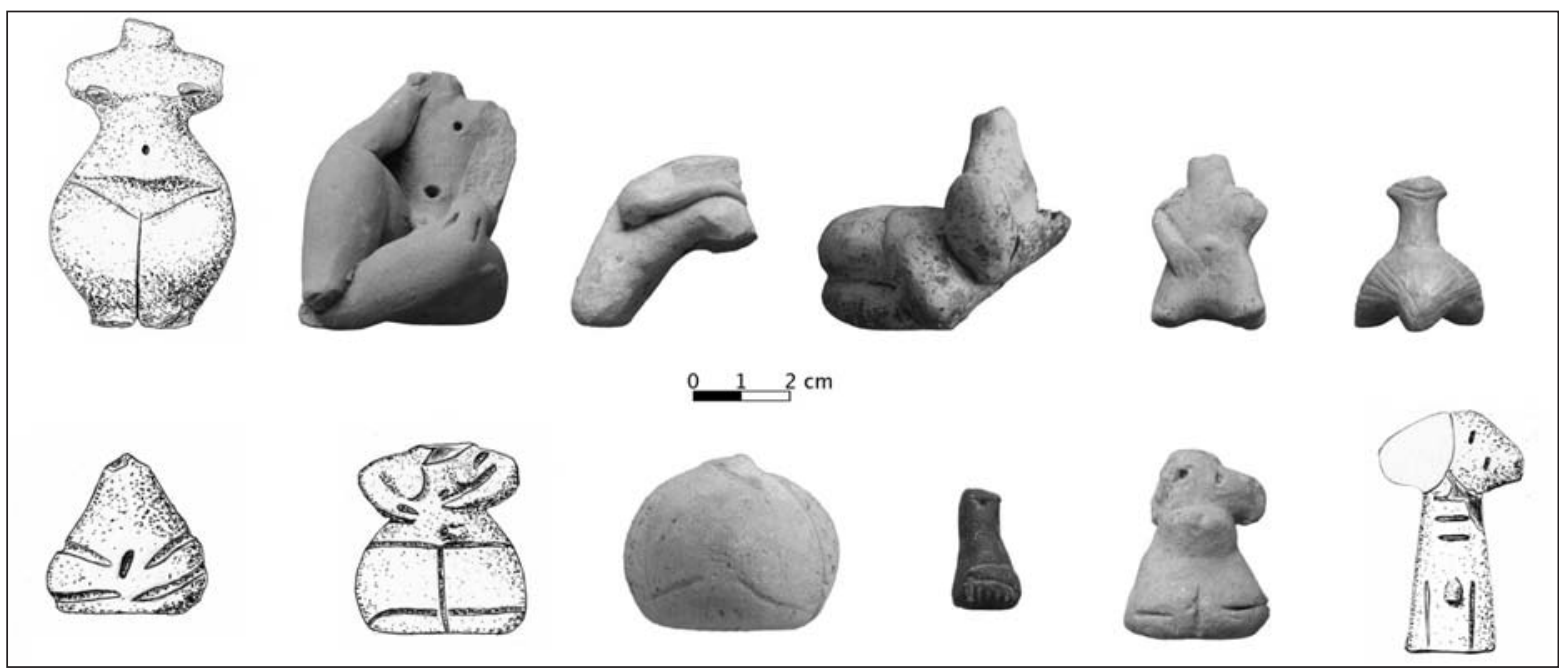

Fig. 2. Characteristic types of figurines from earlier Neolithic sites in Thessaly. (Photos and drawings by the author.).

Relevant to this point is the way humans are represented in the two regions. In the central Balkans, figures are mostly rendered without detail (see Gimbutas 1976 for Anza; Demoule and Lichardus-Itten 1994 and Lichardus-Itten et al. 2002 for Kovačevo; Radunčeva et al. 2002 for Rakitovo; Hiptmair 1997 for Karanovo, Vajsov 1998 for northeastern Bulgaria; Letica 1988 for Divostin; and Karmanski 2005 for Donja Branjevina). Legs and hands, when present, seem to be there only to make their existence apparent (Nanoglou 2008a.9). In contrast, in northern Greece, legs and hands are always present and doing something. Nearly all the figures have their legs and hands in a specific posture/gesture. There is enough variation to suggest that they are not manifestations of a single type, and at the same time, there is enough repetition to suggest that groupings can be made (see Nanoglou 2005). Specific gestures and postures are more frequent in some regions than others, but there are no gestures or postures exclusive to any region (Nanoglou 2006). This might indicate that these gestures and postures were meaningful in relation to each other, a point that resonates with the fact that some figurines are found in groups (see above), suggesting that this variety can be interpreted as connoting different actions on behalf of the figures (Nanoglou 2005; 2008a.8).

So people in the central Balkans were brought to life and socialized in a landscape with generic images of humans and animals, whereas in northern Greece they encountered a landscape populated with active human figures. However the artefacts were used and discarded, they provided a different framework in each region for social life to continue. Their contexts of use and discard are, of course, critical for an un- derstanding of the exact way they were brought to bear upon people's lives, and the lack of information on them is a great loss, but in any case their differences can be informative as such. To say the least, these different frameworks would have enabled and compelled their users to attain a different ontological status in each region. In the central Balkans, the body was invoked as a generic form and in conjunction with animals, highlighting perhaps humanity as such or a certain group identity, which also included animals (see also Bailey 2000 and 2005 for the idea that figurines negotiated the boundaries of the community). In northern Greece, however, the body was always in action, in a way making activity the normal case, naturalizing this particular body. Even if figurines were used only in specific instances, their effect on people would have exceeded their boundaries, and each time, these instances served as reference points (even negative ones) for other activities (Nanoglou 2005.147; 2008a.10). So, even if active bodies were the norm for the contexts where figurines were used and these contexts were specific and limited, figurines would have evoked certain responses from their users (conscious or not) even outside these contexts, if only to define such an exterior. In any case, these contexts would have formed scenes, where people and other entities (animals, plants, stones, artefacts, etc.) would have converged, and where people would have addressed all the rest in ways conditioned - at least to a certain extent - by the figures. That does not mean necessarily that people would have imitated the movements depicted by the figures. But the materiality of the figurines would have certainly been taken account of; their presence would have been accounted for. 
It is a completely different thing to account for figures that bring forth generic notions of humanity and animality (or a combination of these, see Nanoglou 2008a. 5) and figures that focus on what people do. They evoke different questions: on the one hand: 'What or who are you to expect a certain position in this world?' (a 'what or who' that evidently concerns animals, too); on the other hand: 'What do you do, to attain such a position?' (Nanoglou 2008a.9). These questions, these accounts, are not merely explanations after the fact. They are not present to inform on an already achieved condition. They are rather constitutive of the ontological status of the people that engage in such scenes and, by correlation, of the people that do not. This means that people in the two regions would have been constituted as subjects in different ways and in a different world. Can we be more specific on the issue? Perhaps, up to a certain point, and considering the generalizing level of this exploration, we could suggest that, trying to cope with animals, plants, their built and unbuilt environment, the land and its resources or whatever, people in the central Balkans paid special attention to the position of humans and animals within this web of relations. This might resonate with the somewhat loose architectural definition of community space in the central Balkans (Bailey 2000; 2005. 4-5) and the suggestion that in flat, extended settlements, animals were held inside the occupation area (Chapman 1989; Andreou \& Kotsakis 1994). Perhaps both of these practices, the incorporation of animals in the occupation area and in the representational field, could be interpreted as part of their incorporation in a common identity, as Bailey has already suggested (2000). Yet, rather than expressing such an identity, figurines constituted it, bringing together diverse entities (at least from our point of view) and normalizing their fusion. In northern Greece, such a fusion does not seem to have been in the foreground. Figurines seem concerned with the actions of people, especially actions performed collectively, and this again might resonate with the way the built environment was organized, resulting in settlements with packed buildings and limited open air space (Kotsakis 1999). ${ }^{4}$ Perhaps, then, architecture and representational practices instigated the constitution of a communal identity different from the one in the central Balkans, which was centred on the relation of humans and animals, focusing instead on the relations between humans and realizing a community whose distinctive trait was to perform certain actions. The distinctiveness of this process in each case and the specific identities it constituted need to be explored on a more local level, bringing forth the particularities of each context of use, but for the moment it seems unavoidable to conclude that the inhabitants of the two regions did not live in the same world.

\section{Rearticulating the tradition: the later Neolithic}

In both regions, there are many changes observed in the assemblages of the later Neolithic. To follow these changes gradually is difficult, both in view of the space available and the danger of presenting a

\footnotetext{
4 An important caveat: there are still no published assemblages from earlier Neolithic flat extended settlements in northern Greece, which might prove to be inconsistent with this suggestion. All figurine assemblages known to me during the writing of this paper come from settlements with intensive habitation, regardless of their turning to tells or not (see Nanoglou 2008c.146 for this matter and a call to focus on the process of rebuilding, rather than the final outcome of this process).
} 
circular argument as long as we rely on these very changes as chronological markers. So, rather than trying to present what came first and second, I will focus again on the general traits of the period and especially the first half of the fifth millennium BC. In the case of northern Greece in particular there is a further reason to do so. Regarding Thessaly, published data from Late Neolithic assemblages dating to the second half of the sixth millennium $\mathrm{BC}$ (the 'pre-Dimini phases', see note 2) are not that common and, indeed, most of our information on the later Neolithic comes from assemblages dating to the first half of the fifth millennium BC (the proper 'Dimini phases', see note 2). In the rest of northern Greece, namely Macedonia and Thrace, most of the assemblages show a remarkable similarity to the ones from the northern areas (the 'Vinča culture') and so in this period the comparison is between Thessaly and the areas to the North, rather than northern Greece and the central Balkans.

There are certain traits that seem to be present in both areas. Hands are rendered as mere stubs (Tringham 1971.112; Nanoglou 2005.150) and the size of the head is big in relation to the body (Tringham 1971.184 for Vinča and Nanoglou 2008b.323 for Greece), which seems to suggest an emphasis on the head (along with other features, at least for Thessaly, Nanoglou 2005.150-1). Another similarity is a trend towards the standardization of forms: in both areas and despite the variety in a range of details, most of the figurines can be categorized into just a few different types (Pavlović 1990; Nanoglou 2008 . $324)$, evoking more generality than particularity. Certain other features are not so easily comparable. In the first half of the period, figurines from Serbia to Macedonia are mostly standing, and rarely seated (Tringham 1971.112; Milojković 1990.415; Nanoglou 2006.164), a feature that we cannot discern in Thessaly, due to the lack of contemporary assemblages. 5 Towards the second half of the period, it seems that figurines with a solid lower part proliferate in the North (Milojkovic 1990.412; Nanoglou 2004), though standing and seated ones continue (Tringham 1971.184), whereas in Thessaly, figurines with a solid lower part definitely predominate (Nanoglou 2005.150).

The major changes introduced in this period are: a) for Thessaly: i) the dominance of figures that (like the ones in the earlier Neolithic central Balkans) show only a generic human form (Nanoglou 2005), and

ii) the proliferation of stone as a material for the manufacture of figurines (Nanoglou 2008b); and

b) for the northern areas, the use of incisions on many figurines (Tringham 1971; Chapman 1981; Srejović 1988; Milojković 1990; Pavlović 1990).

So, in this period, both areas have figurines that at first sight focus on a generic human form; but this is not exactly the case. First of all, in Thessaly, the generic form comes from the re-articulation of a tradition that focused on specific bodies, which suggests that there was a repudiation of previous practices, a move against them. This move, in conjunction with the proliferation of stone figures, suggests that the interest is no longer in what a body does, but what a body is made of (Nanoglou 2008b.326). Rather than simply generic, the new form is primarily static, and the various figurines are differentiated through their material. Meanwhile, in northern areas, the body remains generic in its form, but is particularized through incisions. A further difference lies in the use of perforations. During the course of the period, figurines with perforated arms seem to multiply in the North (Tringham 1971.185; Nanoglou 2008b.320), whereas in Thessaly they are not that common.

The ratio of human to animal figurines remains relatively unchanged in Thessaly and certain areas with a strong connection to Thessaly during this period (e.g. Makriyalos, Pieria, see Nanoglou \& Pappa forthcoming), whereas to the North, animal figurines are again more frequent than in Thessaly, but not as frequent as in the earlier Neolithic (as evidenced at sites like Sitagroi, Gimbutas 1986; Selevac, Milojkovic 1990; or Divostin, Letica 1988). This could be explained partly as a continuation of the previous tradition. On the other hand, animals are very much represented in other media, especially vessels, suggesting that animals were invoked in a quite different manner in this period (Nanoglou 2009).

So, there are certain features that reiterate the traditions of the earlier Neolithic and there are other features that introduce radical changes into the iconographic landscapes of the areas under examina-

\footnotetext{
5 It is interesting to note that most of the few figurines definitively dated to this phase are either standing (Wace and Thompson 1912.Fig. $71 \mathrm{~b}$ and $76 \mathrm{l}$ from Tsangli) or seated (Gallis 1985 from Platia Magoula Zarkou, which also are very early in the period). But they are not enough for a stronger argument.
} 
tion. As already said, there is variation within the regions I have been comparing in either period, but I am going to focus on practices that seem to be found over wider areas. As I will argue further below, this does not mean that the differences described here correspond to the essential character of two 'cultures' that occupied two neighbouring areas. The differences I describe and the areas constituted by them are partly conditioned by the level on which I have chosen to study the whole area. That said, it seems significant that on this level certain differences do emerge and these point again towards the existence of different worlds.

In Thessaly, the break with the previous tradition seems more radical. The denial of movement and preoccupation with the materials one is made of suggests a major change in the way people understood themselves. The ontological questions posed by these artefacts, in the contexts they were used, were concerned not with the actions of people, but with their making (Nanoglou 2008b; see also Nanoglou 2005. 152). In the northern areas, changes seem radical on a different level. The proliferation of incisions suggests that the generic form of the body is no longer adequate for the contexts where figurines were used. These bodies needed further features in order to be of some use in the various scenes where they were invoked. Even though not all figurines were marked with incisions, those that were incised rearticulated the whole field of representation. At least these called for a change in the way bodies were constituted, not least by setting up an 'opposition' to those that were not incised. The act of incision suggests, perhaps, that the focus was on the surface of the body. That what was significant was the appearance of an incised body, a body that looked a certain way. The discussion on whether the incisions should be interpreted as clothing or something else is old (Milojkovic 1990.412-3) and not yet resolved, but the focus on the surface was meaningful, regardless of what the incisions referred to.

So we can discern changes in both areas. On a certain level, these changes have resemblances. A more or less static image is projected, and an interest in appearances and the head can be detected. On another level, though, differences prevail, both on account of the specific history that representation as a practice had in each region and on account of the specific materiality of the objects in question. Thus, we can suggest that the Thessalian figurines emanate a preoccupation with the substances of which they were made. But this preoccupation should not be in- terpreted as a move to distinguish between interior and exterior, as the use of the material as a differentiating feature could suggest a conflation of our epistemological categories of substance and appearance, with their material being their form (Nanoglou $2008 b .326,329)$. So, the interest seems to have lain in the construction of these entities, and we could perhaps suggest that this also reveals a concern with the past, with the way things came to be what they were (Nanoglou 2008b.325, for pertinent ethnographic material see Ingold 2000.113 and Descola 1996.88), something that resonates with processes seen in other social fields in later Neolithic Greece (Nanoglou 2001.313; 2008b.325). In this vein, the figures from Thessaly constituted an iconographic landscape whereby people would have been able, and perhaps compelled, to identify themselves with reference to their making and their origins.

The figures to the North of Thessaly do not seem to share these concerns. First of all, they seem to have rarely used stone as a material. It seems that clay continued to be seen as the appropriate material for their manufacture. Second, they are static and perhaps generic, but they are particularized through the use of incisions (at least some of them). Incision (and its fellow concept, inscription) has at present some very powerful connotations of an act exercised from outside. It is no accident that this notion is in the middle of discussions pertaining to the meaningfulness of bodies (for the most comprehensive and thorough study yet, see Meskell 1999). Incision/inscription is considered a process whereby meaning is inscribed on an already formed body, as if matter preceded mind. I would suggest that, to a certain extent, incision/inscription is an action upon something, but this something cannot be considered already formed. It is not an act upon a body, but the rearticulation of something into a body. Furthermore, this very practice is what constitutes a surface, as long as we understand inscription/incision as acting on a surface. More importantly for our case, this surface does not need to invoke an underground, even less an underground where this essential character remains hidden (as in the body, which behind appearances is purportedly always the same biological entity). What seems significant is that these figures had to carry certain insignia in order to be appropriate for their use (whatever that was). Their material and their generic form were no longer enough, as they probably had been in the earlier Neolithic. These insignia were part of the body and, as such, they presented a particular body, one that had to be covered with them, one that had to carry them and 


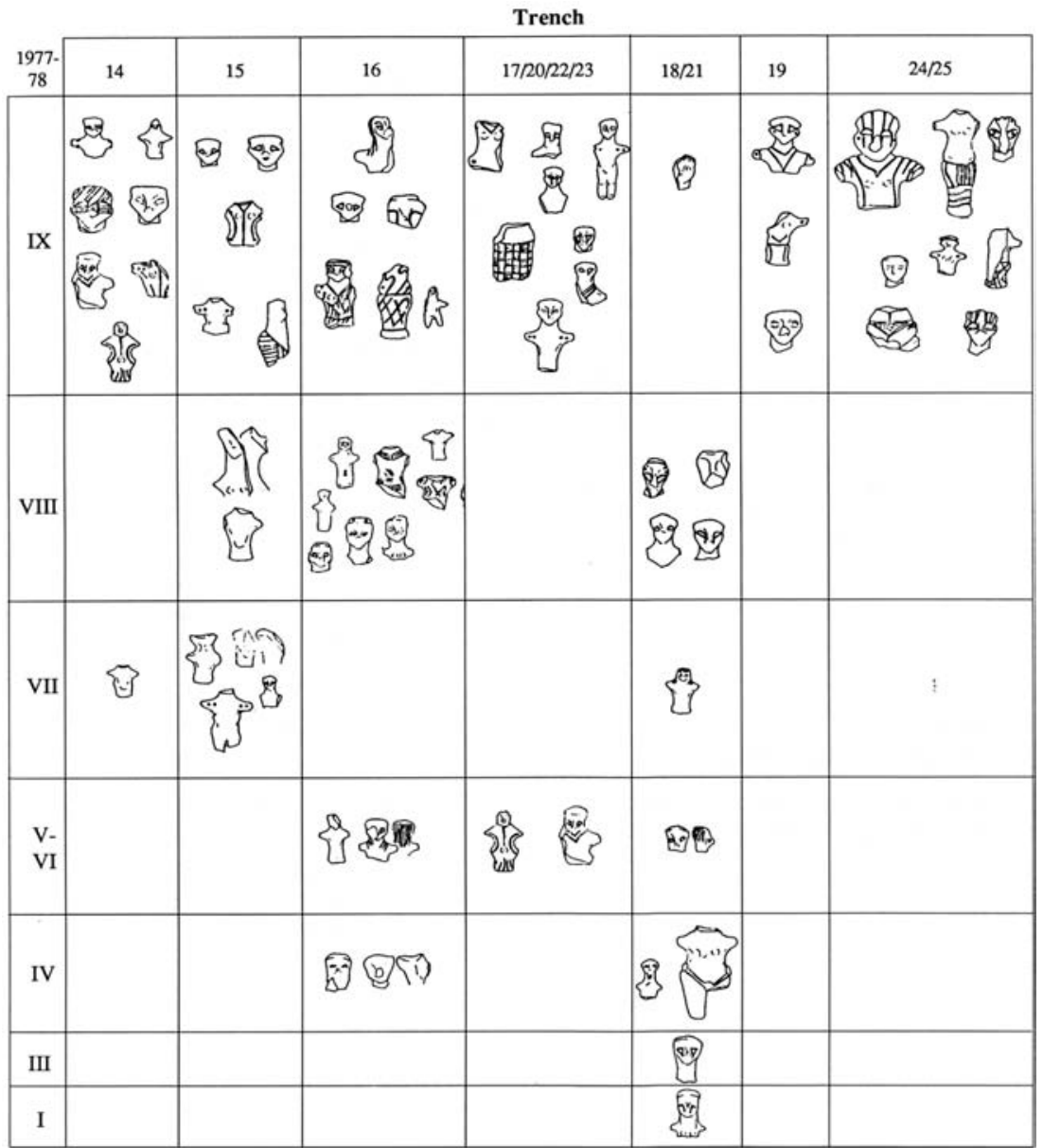

Fig. 4. Chart with characteristic figurines from each phase in the 19771978 excavation area at Selevac. (Reproduced with permission from $R$. Tringham and D. D. Krstić (eds.) 1990. Selevac: a Neolithic village in Yugoslavia (Monumenta Archaeologica 15). The Cotsen Institute of Archaeology, UCLA. Los Angeles (CA): Fig. 11b.).

reveal them so as to be meaningful. It is perhaps not incoherent to suggest that within the context of their use these figures invited the presence of 'incised' persons, of persons covered with relevant insignia, and their place in the social network of the community was recognized and acknowledged with reference to these insignia.

Information about the contexts where these figurines were invoked is scarce indeed. In the area North of Thessaly, there are occasionally groups of figurines found in pits (Tringham and Conkey 1998), but these seem to be assemblages formed through the clearing of areas, rather than purposeful depositions of sets of artefacts as in the above mentioned earlier Neolithic cases in Greece. Whenever we have information, it seems that figurines were not deposited in large numbers (Letica 1988 for Divostin; Nanoglou and Pappa forthcoming for Makriyalos). Even in cases of figurines discovered in large numbers in some features, their deposition corresponds to a gradual accumulation of layers, rather than a single event (e.g. Makriyalos pit 212, Pappa 2008 and PromachonTopolniča pit 4, KoukouliChrysanthaki et al. 2007). Their deposition in fragments (Tringham and Conkey 1998; Chapman 2000; Chapman and Gaydarska 2007) and usually in refuse pits (Tringham and Conkey 1998) suggests that their final disposal was different from that reserved for the earlier Neolithic figurines from Greece (at least for some of them, see above). There are, of course, exceptions (Letica 1988.179 for Divostin, where a group of seven intact figurines was found in House 23). 6 The extensive use of perforations, from which they could presumably be hung, points to a different use-life for these artefacts. We do not need to interpret them as amulets hung from someone's neck (although this is a valid suggestion), for the perforations could serve to fasten many together. But in this case, their fastening was deemed unnecessary for their final deposition.

The information on the contexts of figurine use from Thessaly is even more frustrating, for there is virtually nothing to rely on apart from the case of Platia Magoula Zarkou, where a building-model with eight figurines was found under a floor (Gallis 1985) and two figurines were found in the area of the cemetery (Gallis 1982). But this find is actually dated very late in the earlier Neolithic or very early in the later Neolithic and can be included in the earlier tradition (see Nanoglou 2005.149 for a discussion). Most of the studies are too old and they provide only catalogues of the finds, with only general information on contexts of discovery. Moreover, even stud-

6 Compare also the group of figurines found in a house of phase IX in Ovčarovo, northeastern Bulgaria (dated around the middle of the fifth millennium BC, Todorova 1982.67). 
ies which are supposed to focus on the distribution of the figurines provide no details that could help determine the process of deposition (e.g. Skafida 1992; see Nanoglou 2005.151).

So other than suggesting that these artefacts would have provided points of reference for the deployment of practices in various social fields, there is not much to go forward. Even at this non-specific level, the iconographic landscapes constituted through these artefacts were different in the two areas, and so was the inhabitation of these landscapes. People would have been enabled and compelled to account for themselves by drawing upon different resources. As long as people needed to situate themselves within their community, this would have been possible only through invoking the particular representations present at hand. So, asking about and accounting for one's making would have been essential, at least in certain instances, for someone to go on living. However this was translated (e.g. origins, kinship, etc.), the consequences would have been paramount for someone's life and place in the community. It would have affected the ontological status of the person in question, the way s/he understood herself/himself and others and the way s/he was understood by others. The same applies to asking about and accounting for in terms of insignia. This would have also been significant for someone's life and place in the community. It would have also touched upon the ontological status of the person in question. But the persons would have been different - one constituted in relation to concerns about her/his past, about the process that brought her/him in that position, the other constituted in relation to concerns about the visibility of her/his marks. As different persons, they would also have inhabited different worlds.

\section{One Neolithic, two Neolithics, three Neolithics...}

That the Neolithic is nothing more than an analytical concept, a heuristic device, should be a commonplace by now (see especially Whittle 2003), although many studies still reify the period, attributing to it an essential character, longing for a hard core to emerge, which can be observed, described and followed through regions (Kotsakis 2002). If we agree that the Neolithic was not a stage in the evolution of mankind, an essential economic background upon which social life was built, but a modern concept helping us to grasp our history and our place in the world, constituting in the process the very world we are inhabiting, then the question is: what kind of world did the people of the past inhabit and what kind of concepts did they use to understand it and position themselves within it? In this process, artefacts are and were the co-producers of the world (Meskell 2008.375, following Latour 1993). As long as these artefacts are different and in different associations, in different assemblages (Latour 2005), the worlds produced are bound to be different. There are many Neolithics (as products of our own endeavour to understand our past and our present) and there were many 'Neolithics' (as products of their endeavour to understand their past and present).

People in the southern Balkans inhabited a landscape populated with other people, animals, plants, rocks, rivers, mountains and other entities and features and were called upon to account for them and for themselves as they encountered other beings (human or not). Drawing upon previous practices, they were called to make choices and reiterate certain practices that were deemed appropriate for contingent events. During the earlier Neolithic in the Balkans, people manufactured clay figurines, clay objects citing human and animal beings, and used them on occasions that cannot be adequately described. Yet, whatever these occasions were, figurines would have been points of reference for the conceptualization of themselves and others. Communities living in Thessaly focused significantly on citing humans and their actions in clay. Growing up in these communities, someone would have been compelled to focus on exactly these features and define herself/ himself according to relevant criteria. This defining process was conditioned by the circumstances, the contexts of use of the artefacts. Reiterating the artefacts would entail commemorating to a small or large extent these circumstances, the spacetimes where the artefacts were articulated and re-articulated within the fabric of social life. This commemoration would have ensured that the spacetimes would have been extended (Munn 1980) and similarities would have covered greater regions. In fact, this commemoration would have constituted regional identities, as it would have served as a defining trait for a group of people and a group of communities (see Nanoglou 2006). So, people to the North probably focused on different features, citing both people and animals in clay and concentrating on their generic images, rather than on their actions. They were commemorating different instances, different scenes where people, animals and other beings (animate or inanimate) engaged with each other. In these instances their relation to animals was probably deemed quite important. Extending different spacetimes, each group of people and communities constituted two 
different regions where a distinctive world was produced. In the first case, a world assembled with reference to human actions; in the second, a world revolving around the relation between humans and animals, or perhaps something that transcended the two categories as we moderns understand them (see Nanoglou 2008a.5 and Meskell 2008). It is perhaps no coincidence that in the first case people lived in densely populated settlements (Kotsakis 1999), whereas in the second, the organization of settlements was somehow looser (Bailey 2000; 2005.4-5; see Nanoglou 2008a.8 and the caveat ibid note 9). What constituted a viable or desirable community would have been contingent on the practices that focused on what constituted a viable or desirable body. If the reference points for the community included animals, then animals should probably have been present in the community space (Chapman 1989 for the interpretation of flat extended settlements as inclusive of pasture areas). On the contrary, if the focus was on people's actions and their monitoring, then an appropriate spatial arrangement should have been provided.

For the people in these two regions, carrying out everyday tasks would have differed. Even though agricultural regimes no longer seem so different in the two regions (Bogaard 2004), it does not mean that representational practices were mere variations on a common theme. On the one hand, figurines in Greece do not seem to delve into the subject of domestication (Nanoglou 2009). The artefacts seem to cite practices pertaining to other facets of life in these communities. Consequently, these facets were defined as separate social fields through their citation by figurines. They were constituted and conditioned by these artefacts, which at the same time constituted and conditioned these fields. There people would have been requested to focus on their actions in the presence of others. And their life and their world would have revolved, at least to some extent, around these spacetimes, allowing them and perhaps compelling them to define themselves as participants or not, or as successful or unsuccessful contributors, etc. Meanwhile, figurines to the North touch upon the subject of human-animal relations. This does not mean that they probe the issue of domestication, but it is evident that in fields defined by the use of these artefacts the interest was not just in people. It is not clear whether people and animals were considered opposed or not in these scenes (Nanoglou 2008a.5). We could see it as the negotiation of a certain hybridism (see Meskell 2008 on Çatalhöyük), but that must remain purely hypothetical for the moment. The important thing is that they were concerned only with the generic image of the human and animal body, with their presence as such, and thus people would have been guided to define themselves accordingly. Actions were perhaps irrelevant - what really mattered was the position one held in this spectrum of possible relations between persons and animals. Consequently, people were constituted along different trajectories in the two regions. Their ontological status - who they were, what they were - was contingent on their understanding of these artefacts and the definition of a place for themselves according to this understanding. In order to act socially it was necessary that their very being was intelligible and sanctioned, which was only possible through adherence to the discourses materialized by the figurines (among others, of course), even in order to subvert them.

Following upon these distinct traditions, the inhabitants of the two regions rearticulated them in the centuries that ensued. Yet again, two regions were defined by the very reiteration of practices over space, by the extension of specific spacetimes. That the regions were not the same as before underlines the argument that these regional identities had to be performed in order to persevere. The changes in the artefact assemblages of a certain region can be explained as changes in the commemoration of the spacetimes that were valued and deemed important for the social life of the inhabitants. People were starting to invoke different practices and different artefacts in their various encounters with each other or with other creatures and entities. The same process that allowed material culture to change over time allowed it to change over space too. In each new encounter a rearticulation of the previous moments was bound to happen, and yet it was contingent on the choices made.

These changes suggest a radical break with the past in Thessaly. The concern with acting bodies was dropped, and people focused on the material of the figures. I have argued that this could be interpreted as a concern with the making of the figures and, by extension, with the making of their users. So, from a discourse that focused on the actions that were presented and, consequently, the present, we turn to a discourse that focused on origins and the past. This resonates with changes occurring in other social fields, especially the manipulation of the form of a settlement to resemble a long-lived tell (Nanoglou $2001 ; 2008 c$ ). This does not mean that tells were exclusively related to such constructs, since this was obviously not the case (Vinča being an excellent exam- 
ple). It does mean that a certain concern with the origins of people and of their communities was acquiring a central position in the social life of the inhabitants of Neolithic Thessaly, and that they would have experienced this life through such a pervasive prism.

To the North of Thessaly, such concerns are not evident, at least to us. Appearance seems to have been a major classificatory principle for figurines and consequently for people too. This could have been anchored in the past, namely in the way appearances were inherited and reproduced. But the significant feature here seems to be the need to monitor someone's place in the community. Seen this way, it is not opposed to the previous tradition of the region, but it does certainly rearticulate it to a great extent, directing attention to a particular plane of the body, its surface (again: not necessarily opposed to a deep core). This concentration on the surface and its incision resonates, perhaps, with relevant practices in the production of pottery. Vessels were widely incised and, indeed, the relation between the incisions on pottery and on figurines has been noted (see $\mathrm{Mi}$ lojković 1990.413 citing Srejović 1968). It is perhaps significant that in communities sharing this type of figurines, vessels with human and animal features are common (Pileidou 2006; see Nanoglou 2009). It seems that there existed a strong relation between figurines and pottery, one that focused among other things on the organization of their appearance through incision. It is perhaps equally significant that in this region figurines continued to be made almost exclusively of clay, reinforcing the relation between the two classes. There are, of course, differences between them: first of all it seems that the ratio between humans and animals was inverted in pottery, where vessels with animal features outnumber vessels with human features (Nanoglou 2009 for northern Greece). So, in an expanded field of representation, which includes both figurines and vessels, it seems that humans and animals are indeed again a major theme, continuing from a previous tradition. But in this case, humans and animals are constrained to a great extent within a subfield of their own: figurines predominantly for humans, vessels predominantly for animals. Humans and animals continue to be paired when it comes to representations, but they are constituted as different sub-species through the artefacts that cite them. Animals seem to be defined as containers (Nanoglou 2009), whereas the use of perforations might allow us to suggest that humans were considered, at least in some instances, as something to be carried around.

So people drew upon different material resources and produced themselves as diverse persons, as diverse kinds of persons. In the same process, they were producing different worlds, not just different worldviews, but different entities, different creatures. It was one thing to be a human or an animal in Thessaly, and another to the North. It is important to insist on the matter: the issue is not about a Neolithic regime that is understood and felt differently by various agents, but about the production of different regimes and different constituents (different animals, different plants, different people, different resources, etc.), even different kinds of constituents (taxonomies different from 'animals', 'plants', 'people', etc.). In each region, people, animals or any entity had a different presence in their world. They were able to be present, to situate themselves and others in the world, to act and react as something different.

There was, of course, no rigid boundary between regions. Boundaries were performed as people commemorated specific spacetimes and reiterated specific practices. The two regions I have been describing in this paper are to a large extent a product of my own research. The case of Makriyalos is eloquent: from a community sharing many similarities with the northern area in the first half of the Late Neolithic, it turned into a community sharing many features with Thessaly in the second half of the period (Pappa and Besios 1999; Pappa 2008). Yet this was not a case of changing sides, but a rearticulation of the community's own past, since many of the traits encountered in the first phase are present in the second. In Makriyalos, as in any other case, people did not merely join or leave a 'culture', but produced an inhabitable place by citing previous experiences. The very context of citation was conditioned by these experiences and people's ability to reiterate them, and at the same time, fail to reiterate them.

\section{ACKNOWLEDGEMENTS}

I would like to thank Prof. M. Budja for inviting me to contribute to this volume. I am also grateful to Lynn Meskell for looking through the text at a very short notice. Standard disclaimers apply. 


\section{REFERENCES}

ANDREOU S., FOTIADIS M., KOTSAKIS K. 1996. Review of Aegean prehistory V: the Neolithic and Bronze Age of northern Greece. American Journal of Archaeology 100: 537-597.

ANDREOU S., KOTSAKIS K. 1994. Prehistoric rural communities in perspective: the Langadas survey project. In P. Doukellis and L. G. Mendoni (eds), Structures rurales et sociétés antiques. Actes du colloque de Corfou, 14-16 mai 1992. Annales Littéraires de l' Université de Besancon 508. Centre de Recherches d'Histoire Ancienne, Paris: 17-21.

AUSTIN J. L. 1962. How to Do Things with Words. Clarendon Press. Oxford.

BAILEY D. W. 2000. Balkan Prehistory: Exclusion, Incorporation and Identity. Routledge. London.

2005. Prehistoric Figurines: Representation and Corporeality in the Neolithic. Routledge. London.

BARRETT J. C. 1994. Fragments from Antiquity: an archaeology of social life in Britain, 2900-1200 BC. Blackwell. Oxford.

2005. Material culture, humanity and the beginnings of the Neolithic. In TL. Kienlin (ed.), Die Dinge als Zeichen: kulturelles Wissen and materielle Kultur. Habelt, Bonn: 111-24.

BOGAARD A. 2004. The nature of early farming in Central and South-east Europe. In M. Budja (ed.), 11th Neolithic Studies. Documenta Praehistorica 31: 49-58.

BUTLER J. 1993. Bodies that Matter: on the Discursive Limits of 'Sex'. Routledge. New York.

1997. Excitable Speech: a politics of the performative. Routledge. New York.

CHAPMAN J. 1981. The Vinča Culture of South-East Europe: studies in chronology, economy and society. BAR IS 117. Oxford

1989. The early Balkan village. In S. Bökönyi (ed.), Neolithic of Southeastern Europe and Its Near Eastern Connections. International Conference 1987. Szolnok-Szeged. Varia Archaeologica Hungarica II. Institute of Archaeology of the Hungarian Academy of Sciences, Budapest: 33-43.

2000. Fragmentation in Archaeology: People, Places and Broken Objects in the Prehistory of South Eastern Europe. Routledge. London.

CHAPMAN J., GAYDARSKA B. 2007. Parts and Wholes: Fragmentation in Prehistoric Context. Oxbow. Oxford
DEMOULE J.-P., LICHARDUS-ITTEN M. 1994. Fouilles franco-bulgares du site néolithique ancien de Kovačevo (Bulgarie du Sud-Ouest): rapport préliminaire (campagnes 1986-1993). Bulletin de Correspondance Hellénique 118: $561-618$.

DERRIDA J. 1982. Signature event context. In D. Derrida, Margins of Philosophy. Translated with additional notes by A. Bass. The University of Chicago Press, Chicago: 309-330.

DESCOLA P. 1996. Constructing Natures: Symbolic Ecology and Social Practice. In P. Descola and G. Pálsson (eds.), Nature and Society: Anthropological Perspectives. Routledge, London: 82-102.

FELMAN S. 2003. The Scandal of the Speaking Body: Don Juan with J. L. Austin, or Seduction in Two Languages. Translated by C. Porter, with a new Foreword by S. Cavell and Afterword by J. Butler. Stanford University Press. Stanford.

GALLIS K. 1982. Kafseis Nekron apo ti Neolithiki Epochi sti Thessalia. Archaeological Receipt Fund. Athens.

1985. A Late Neolithic foundation offering from Thessaly. Antiquity 54: 20-22.

GIMBUTAS M. 1976. Figurines. In M. Gimbutas (ed.), Neolithic Macedonia: as Reflected by Excavation at Anza, Southeast Yugoslavia (Monumenta Archaeologica 1). UCLA Institute of Archaeology, Los Angeles (CA): 198240 .

1986. Mythical imagery of Sitagroi society. In C. Renfrew, M. Gimbutas and E. S. Elster (eds.), Excavations at Sitagroi: a Prehistoric village in Northeast Greece Vol. I (Monumenta Archaeologica 13). UCLA Institute of Archaeology, Los Angeles: 225-301.

HIPTMAIR P. 1997. Neolithische Statuetten und figürliche Darstellungen. In S. Hiller and V. Nikolov (eds.), Karanovo: die Ausgrabungen im Südsektor 1984-1992. F. Berger and Söhne, Horn: 255-70.

INGOLD T. 2000. The Perception of the Environment: Essays in Livelihood, Dwelling and Skill. Routledge. London.

JOYCE R. A. 2000. Gender and Power in Prehispanic Mesoamerica. University of Texas Press. Austin (TX).

KARMANSKI S. 2005. Donja Branjevina: a Neolithic Settlement Near Deronje in the Vojvodina (Serbia). Società per la preistoria e protoistoria della regione Friuli-Venezia Giulia, Quaderno 10. Trieste. 
KNAPPETT C. 2006. Beyond skin: layering and networking in art and archaeology. Cambridge Archaeological Journal 16(2): 239-251.

KOTSAKIS K. 1999. What tells can tell: social space and settlement in the Greek Neolithic. In P. Halstead (ed.), Neolithic Society in Greece. Sheffield Academic Press, Sheffield: 66-76.

2002. Review of C. Perlès, The Early Neolithic in Greece. European Journal of Archaeology 5: 373-377.

KOUKOULI-CHRYSANTHAKI CH., TODOROVA H., ASLANIS I., VAJSOV I., VALLA M. 2007. Promachon-Topolnica: a Greek-Bulgarian archaeological project. In H. Todorova, M. Stefanovich and G. Ivanov (eds.), The Struma/Strymon River Valley in Prehistory. In the Steps of James Harvey Gaul 2, Gerda Henkel Stiftung, Sofia: 43-67.

LATOUR B. 1993. We Have Never Been Modern. Translated by. C. Porter. Harvard University Press. Cambridge.

2005. Reassembling the Social: an introduction to Actor-Network-Theory. Oxford University Press. Oxford.

LETICA Z. 1988. Anthropomorphic and zoomorphic figurines from Divostin. In A. McPherron and D. Srejović (eds.), Divostin and the Neolithic of Central Serbia. University of Pittsburgh Department of Archaeology, Pittsburgh (PA): 173-87.

LICHARDUS-ITTEN M., DEMOULE J.P., PERNIČEVA L., GREBSKA-KULOVA M., KULOV I. 2002. The site of Kovačevo and the beginnings of the Neolithic period in southwestern Bulgaria. In M. Lichardus-Itten, J. Lichardus and V. Nikolov (eds.), Beiträge zu jungsteinzeitlichen Forschungen in Bulgarien, Habelt. Bonn: 99-158.

MESKELL L. 1995. Goddesses, Gimbutas and 'New Age' archaeology. Antiquity 69: 74-86.

1999. Archaeologies of Social Life: age, sex, class et cetera in ancient Egypt. Blackwell. Oxford.

2004. Object Worlds in Ancient Egypt: material biographies past and present. Berg. Oxford and New York.

2007. Refiguring the corpus at Çatalhöyük. In C. Renfrew and I. Morley (eds.), Image and imagination: $a$ global prehistory of figurative representation. McDonald Institute of Archaeological Research, Cambridge: 137-149.

2008. The nature of the beast: curating animals and ancestors at Çatalhöyük. World Archaeology 40(3): 373-389.
MILLER D. 1987. Material Culture and Mass Consumption. Blackwell. Oxford.

2005. Materiality: an introduction. In D. Miller (ed.), Materiality. Durham and Duke University Press, London: 1-50.

MILOJKOVIĆ J. 1990. The anthropomorphic and zoomorphic figurines. In R. Tringham and D. Krstić (eds), Selevac: a Neolithic village in Yugoslavia. Institute of Archaeology, UCLA, Los Angeles: 397-436.

MINA M. 2008. Carving out gender in the prehistoric Aegean: anthropomorphic figurines of the Neolithic and Early Bronze Age. Journal of Mediterranean Archaeo$\operatorname{logy} 21(2):$ 213-239.

MUNN N. D. 1986. The Fame of Gawa: a symbolic study of value transformation in a Massim (Papua New Guinea) society. Cambridge University Press. Cambridge.

NANOGLOU S. 2001. Social and monumental space in Neolithic Thessaly, Greece. European Journal of Archaeo$\log y$ 4(3): 303-322.

2005. Subjectivity and material culture in Thessaly, Greece: the case of Neolithic anthropomorphic imagery. Cambridge Archaeological Journal 15(2): 141-156.

2006. Regional perspectives on the Neolithic anthropomorphic imagery of northern Greece. Journal of Mediterranean Archaeology 19(2): 155-176.

2008a. Representation of humans and animals in Greece and the Balkans during the earlier Neolithic. Cambridge Archaeological Journal 18(1): 1-13.

2008b. Qualities of humanness: material aspects of Greek Neolithic anthropomorphic imagery. Journal of Material Culture 13(3): 311-334.

2008c. Building biographies and households: aspects of community life in Neolithic Northern Greece. Journal of Social Archaeology 8(1): 139-160.

2009. Animal bodies and ontological discourse in the Greek Neolithic. Journal of Archaeological Method and Theory 16(3): 184-204.

NANOGLOU S., PAPPA M. forthcoming. Anthropomorphic imagery from Neolithic Makriyalos. To Archaiologiko Ergo sti Makedonia kai Thraki. 20 years Anniversary Volume.

PAPPA M. 2008. Organosi tou Horou kai Koinotika Stoicheia stous Neolithikous Oikismous tis Neolithikis Makedonias. Unpublished PhD Thesis. Aristotle University of Thessaloniki. Thessaloniki. 
PAPPA M., BESIOS M. 1999. The Neolithic settlement at Makriyalos, Northern Greece: preliminary report on the 1993-1995 excavations. Journal of Field Archaeology 26: $177-195$.

PAVLOVIĆ M. 1990. The aesthetics of Neolithic figurines. In D. Srejović and N. Tasić (eds), Vinča and its World: International Symposium on the Damubian Region from 6000 to 3000 B.C., Belgrade, Smederevska Palanka, October 1988. Serbian Academy of Sciences and Arts, Belgrade: $33-4$.

PILEIDOU K. 2006. I neolithiki anthropomorphi aggeioplastiki ton Valkanion. Unpublished PhD Thesis. Aristotle University of Thessaloniki, Thessaloniki.

RADUNČEVA A., MACANOVA V., GATSOV I., KOVACHEV G., GEORGIEV G., CHAKALOVA E., BOZILOVA E. 2002. Neolitnoto selishte do grad Rekitovo. Gal-Iko. Sofia.

REINGRUBER A., THISSEN L. 2005. ${ }^{14} \mathrm{C}$ database for the Aegean catchment (Eastern Greece, Southern Balkans and Western Turkey) 10.000-5500 cal BC. In C. Lichter (ed.), How Did Farming Reach Europe? Anatolian-European relations from the second half of the 7 th through the first half of the $6^{\text {th }}$ Millennium cal BC. Proceedings of the International Workshop Istanbul, 20- 22 May 2004. Ege Yayınları, Istanbul: 295-327.

RENFREW C. 2003. Figuring it out: the parallel visions of artists and archaeologists. Thames and Hudson. London.

2007. Prologue. In C. Renfrew and I. Morley (eds.), Image and Imagination: a global prehistory of figurative representation. McDonald Institute for Archaeological Research, Cambridge: xv-xvi.

SKAFIDA L. 1992. Neolithika anthropomorpha eidolia tou Diminiou. In Diethnes Synedrio gia tin Archaia Thessalia sti Mnimi tou D. R. Theochari. Archaeological Receipts Fund, Athens: 166-79.

SREJOVIĆ D. 1968. Neolitska plastika centralnobalkanskog područja. In Neolit Centralnog Balkana. Narodni Muzej Beograda, Belgrade: 177-240.

1988. The Neolithic of Serbia: archaeological research 1948-1988. Centre for Archaeological Research, Faculty of Philosophy, The University of Belgrade, Belgrade.

TRINGHAM R. 1971. Hunters, Fishers and Farmers of Eastern Europe: 6000-3000 bc. Hutchinson. London.

TRINGHAM R., CONKEY M. 1998. Rethinking figurines: a critical view from archaeology of Gimbutas, the 'God-dess' and popular culture. In L. Goodison and C. Morris (eds.), Ancient Goddesses: the Myths and the Evidence. British Museum Press, London: 22-45.

UCKO P. J. 1996. Mother, are you there? Cambridge Archaeological Journal 6: 300-304.

VAJSOV I. 1998. The typology of the anthropomorphic figurines from northeastern Bulgaria. In M. Stefanović, H. Todorova and H. Hauptmann (eds.), In the Steps of James Harvey Gaul (James Harvey Gaul - In memoriam Vol. 1). James Harvey Gaul Foundation, Sofia: 107-41.

WACE A. J. B., THOMPSON M. S. 1912. Prehistoric Thessaly. Cambridge University Press. Cambridge.

WHITTLE A. 2001. Different kinds of history: on the nature of lives and change in central Europe, c. 6000 to the second millennium BC. Proceedings of the British Academy 110: 39-68.

2003. The Archaeology of People: dimensions of NeOlithic life. Routledge. London. 